\title{
The Data Portal of the German Federal Ministry of Education and Research (BMBF) as part of the German Open Government Approach
}

\author{
Peter Muessig-Trapp ${ }^{1}$, Viktor Skladovs ${ }^{2}$ \\ ${ }^{1}$ The Higher Education Information System Agency (HIS) Hannover, Germany, muessig@his.de \\ 2 The Higher Education Information System Agency (HIS) Hannover, Germany, skladov@his.de
}

Keywords

Open Access, Open data, Open Courseware and Digital publishing, Business Intelligence and University Analytics.

\section{ABSTRACT}

A German online data portal containing tables with statistical data material was launched in early summer 2011. This is offered by the Federal Ministry of Education and Research and implemented by the HIS Higher Education Research Institute. The portal is intended as an information system for research support as well as a data source for ministries, press, businesses and interested private citizens. It offers a wide range of data in the fields of education, research and innovation. The portal covers, amongst others, partially very long time series from the paper based publication „Federal Report on Research and Innovation“ and the former paper series „Basic and Structural Data“. It comprises more than 400 tables from different sources (e.g. Federal Statistical Office, European Union, OECD, Centre for European Economic Research, HIS Higher Education Information System, Federal Institute for Vocational Education and Training). The data portal is regularly updated, namely, several times a year, as soon as recent data is available from any source.

\section{OPEN DATA CONCEPT}

In accordance with the open data concept ("A piece of content or data is open if anyone is free to use, reuse, and redistribute it - subject only, at most, to the requirement to attribute and/or share-alike.", cf. www.opendefinition.org), all tables can be used and distributed without any restrictions regarding copyrights, patents and other proprietary rights. The data portal can be seen as a part of the German open government approach, aimed at realizing modern administration by transparency, cooperation and participation. The data portal is linked by several German open data initiatives and university libraries. At normal working days, the portal is visited by about 200 visitors, an English language version of the most important portal pages is recently available as well.

\section{DATA PORTAL STRUCTURE}

The BMBF's Data Portal (http://www.datenportal.bmbf.de) consists of several parts. The main feature is the table selection that is divided into four basic sections namely General Overviews and Structural Data, Research and Innovation, Education, and International Comparison. To assist data comprehension short introductory texts are added to the four basic sections.

General Overviews and Structural Data offer the social and economic frame to allow a better understanding of the following sections that are divided into further subsections. Section Research and Innovation covers a range of data concerning expenditure on research and development (R\&D), R\&D personnel, R\&D output (publications and patents), and innovations (product and process innovators). Section Education provides information on educational funding and a whole range of educational topics which are pre-primary education, (vocational) schools, higher education, training assistance, and continuing education. The fourth section International Comparison does not contain any data in addition to the other sections but it collects all tables that provide international comparative data. 
In order to ease data finding, each (sub)section is headed by a compact index that links to the corresponding data table. The tables are available in various formats: barrier-free HTML, XLS and PDF. HTML and XLS may provide longer time series than PDF that may be shortened for reasons of clarity and comprehensibility. For the same reasons certain tables are not provided in PDF format at all. Why there are three different output formats? HTML is useful for quick data access, XLS is suitable for further data handling and PDF offers nice-looking prints. Selected tables are supplemented by infographics that come as PDF.

Data cannot be only researched by directly navigating through these thematic sections but also by using the keyword search mechanism which supports the combination of multiple keywords.

In addition, the data portal has a glossary with explanations of certain technical terms and abbreviations to be found on portal pages. Besides the table selection there are two more other approaches to certain data content. The first is a collection of tables that are printed in the BMBF publication Federal Report on Research and Innovation, and the second is an equal table / infographics collection of the publication Education and Research in Figures. Both menu items provide the figures in their original print layout (PDF). Furthermore, there are links to the corresponding tables of the table selection that may contain more detailed information and be of a more current status.

\section{4. edUSTORE / ICE}

One of the most important parts of the data portal is eduSTORE/ICE, an Open Source Software (GPLv3 license), produced by HIS Higher Education Information System Agency.

This is a web-based information system developed and optimized to support higher education

policy decision making. The system is a business intelligence (BI) solution based on a data warehouse and provides a bunch of analytical tools and reporting facilities. eduSTORE is also part of HISinOne (http://www.hisinone.de/en/home), a campus management system, produced by the German public owned non-profit company HIS Higher Education Information System Agency.

In principle, eduSTORE/ICE is able to manage an infinite amount of data that can be systematically accessed and freely combined. The system flexibly suits to given requirements and is able to process data from various sources: data of the official statistics, data of the administrative systems of universities, colleges, and other establishments, labour statistics, survey results...

eduSTORE/ICE is designed to be the long-term memory for statistical data. Unlike operational software systems, it never forgets about previously imported data. For this reason the system is ideal for analytical purposes, especially for creating time series. All data included in the system can be identified by a standardized key-system. This key-system, which harmonizes all of the system's data, equivalence rules, and implication rules, allows sorting and comparing data of various data stocks or - where required - of various sources. All result tables produced with Flexible Table Generator can be stored as so-called ICE user-tables. User-table libraries can be provided for third parties as sources of information either on the Internet or Intranet. The very special feature of the user-tables is the automatic update function. At the push of a button existing tables can be updated with data that had been imported to the system on a later date.

The portal project team uses eduSTORE/ICE tools primarily for importing data into a database and generating html and excel table output formats offered in data portal.

\section{REFERENCES}

BMBF's Data Portal (2013). Data Portal of German Federal Ministry of Education and Research (BMBF), http://www.datenportal.bmbf.de/.

ICE homepage (2013). The Information System ICE, http: / /ice.his.de/ice/index_en.php.

Peter Müßig-Trapp, Hans Dicken, Ajantha Ratnayake (2010): International Cooperation in Open Source Software Development with the Decision Support System eduSTORE. Presentation at the EUNIS conference, Warsaw, Poland (23 - 25 June 2010), Warsaw, 2010, http://www.pmt.net/publications/\#eunis2010. 


\section{AUTHORS' BIOGRAPHIES}

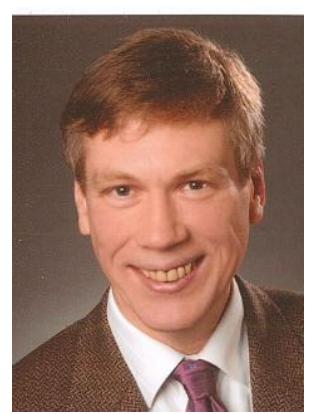

Peter Muessig-Trapp has worked for The Higher Education Information System Agency (HIS) in Hannover, Germany, since 1994, and currently he is the International Account Manager at this company. The basic directions of activity of the company are software development for higher education administrations, higher education research through empirical studies and higher education development (organization, construction, and building).

From 2000 to 2007, as the Head of the section Information Systems and Online Research, Mr. Muessig-Trapp established online research as a part of HIS methodical instruments. On behalf of Germany's Federal Ministry of Education and Research, he launched the Online-Access Panel HISBUS and was also responsible for developing ICE - a web-based information system aimed at supporting higher education policy decisions making assigned by the 16 German states. As the Head of the section Information Systems and Open Source (2008 - 2010) Mr. Muessig-Trapp also was a co-developer of HIS open source strategy.

As an International Account Manager, Mr. Muessig-Trapp has managed various international projects in the field of information systems and open source, in such countries as Guatemala, Sri Lanka, Syria and Lithuania, amongst others.

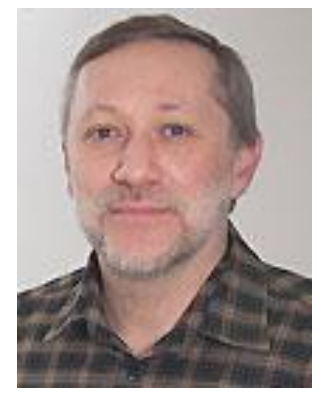

Viktor Skladovs is a software engineer at The Higher Education Information System Agency (HIS) in Hannover, Germany. The company specializes in doing complex researches and developing management software for higher education institutions. As a senior software engineer Mr. Skladovs is responsible for the development of $\mathrm{Bl}$ software solutions produced by the company for the Federal Ministry of Education and Research (BMBF) of Germany. Having graduated from Riga Technical University with the diploma in civil engineering back in 1985, Mr. Skladovs worked for 10 years at the industrial project institute "Latgiproprom" in Riga as a project manager. After moving to Germany and becoming a state certified Computer Scientist at the b.i.b. International College (Hannover), Mr. Skladovs joined the HIS Agency in 2000 as a software developer. 